\title{
An Analysis of Current Graduation Thesis Writing by English Majors in Independent Institute
}

\author{
Ying $\operatorname{Han}^{1}$ \\ ${ }^{1}$ School of Foreign Languages, Zhejiang Gongshang University, China \\ Correspondence: Ying Han, School of Foreign Languages, Zhejiang Gongshang University, Hangzhou City, \\ 310018 Zhejiang Province, China. Tel: 86-135-8877-9372. E-mail: hanyinglucy@163.com
}

\author{
Received: April 6, 2013 Accepted: November 13, 2013 Online Published: December 5, 2013 \\ doi:10.5539/elt.v7n1p120 URL: http://dx.doi.org/10.5539/elt.v7n1p120
}

\begin{abstract}
The paper takes 414 graduates from ZJU in 2011 and 2012, NIT as a case, analyzing the status of their writing of graduation thesis. It is found that a considerable number of students have problems in selection and report of topics, writing of each part and debating in the whole process of graduation thesis. In view of the situation, based on the effective measures and some practical experience by English majors in NIT, ZJU, it is suggested we should raise both teachers' and students' awareness and consciousness in the importance in thesis writing, establish quality management and monitoring system, strictly check selection and report of topics, give play to the library, have topic verification and application guide, being familiar with the writing requirements of the abstract, optimize English curriculum and make professional management features outstanding and enhance the students' and teachers' ability, thereby improving the writing of the graduation thesis and reflecting subject construction in English major.
\end{abstract}

Keywords: English major, graduation thesis, writing, guide

\section{Introduction}

Undergraduate thesis is an essential integral part of the plan in Higher Education Institutions on talents' cultivation, which also plays an essential role in education irreplaceable by other means of teaching. This is a vital standard criterion in assessing undergraduate educational quality in independent institutions. Thanks to the expansion of the higher education in the realm of independent institutions, it bestows students with more opportunities to receive higher education. Meanwhile, there arise such new problems as the quality of education, among which the quality of undergraduate thesis raises great attention from people in both the department of education and administrative level.

Written production is indeed a complicated process (Zimmerman, 2000). It can challenge those writing in L1, but for those writing in a foreign language, the challenges are even greater. Researchers have been showing great interest in graduation thesis writing by English majors. The literature has reached agreement on the principles set by the National Curriculum for College English Programs (2000). The process of thesis writing is more important than the writing result itself. For EFL learners completing a thesis is a big project, which will take up almost every student's last year at university. Effective administration and evaluation methods should be employed to guarantee the progress of the project. Yu's (2001) suggestions on this aspect embody the characteristics and requirements of the English major, and are fairly practical as well. The empirical study on the general state of thesis writing by $\mathrm{Mu}(2001)$ is a survey of 165 college seniors. There are some detailed findings: the majority of the subjects wrote their theses for the sake of fulfilling the requirement, with little appreciation of its real purpose or importance; over half of the survey subjects chose literature as the subject area for their theses; most of the subjects did not realize that research involves looking for references to further their study.

From the above, we know all these researches were kind of partial descriptions. There are few holistic analyses to the main problems in undergraduate thesis writing by English majors in terms of research proposal, writing process consisting of abstract, keywords, contents, research itself, and acknowledgement, and oral defense.

\section{Methodology}

The reviewed literature can not answer the following questions systematically: What is the status quo of thesis writing for English majors? What are the main problems in undergraduate thesis writing for English majors? And 
how to solve these main problems?

Guided by the six rubrics - choosing a topic, preparing a working biology, collecting in formation, outlining the paper, writing the paper, elements of research papers in thesis writing by Slade (2000), this paper is to specify the basic criteria in Thesis Instructions for English Majors from Institutions of Higher Learning (revised edition) (2007) - assess students' English proficiency, assess students' ability in conducting preliminary research in related fields and its specific criteria - scope of the topic, language proficiency, the content of thesis, including its richness, innovation, persuasion of argumentation, convincingness of conclusion, appropriacy of literature, no plagiarism, students' studying attitude.

The researcher will select and analyse 414 undergraduate thesis writing samples by English major students in Ningbo Institute of Technology (NIT), Zhejiang University (ZJU) graduating in 2011 and 2012. Considering the reality of the undergraduate thesis writing by English majors, and by studying the whole process of English major students in NIT and discussing with both graduation theses supervisors and students in NIT, the researcher will present the status quo of undergraduate thesis writing by English majors in terms of research proposal, thesis writing in each part and oral defense. By this means, the researcher will propose suggestions to improve the quality of undergraduate thesis by combining the experience in the practice of effective measures adopted in NIT.

\section{Results}

\subsection{Research Proposal}

\subsubsection{Selecting Research Topics}

According to Fang's (2012) division, this paper divides the research fields in English majors into Linguistics (including study of English and Chinese language and culture, English for specific purposes), Literature, Translation, and Teaching. The researcher will analyse and discuss the problems in research topic selecting process by examining 414 undergraduate thesis samples by English major students in NIT. Problems in selecting research topics are but not limited to these: over-centred topics; a lack of research focus; divergence in goals set by cultivating requirements; a lack of innovation.

\subsubsection{Over-Centred Topic Selection}

Table 1. Types of 203 undergraduate theses by 2011 English majors in NIT

\begin{tabular}{lll}
\hline Types & Total & Percentage \\
\hline Linguistics & 79 & 39 \\
Literature & 62 & 31 \\
Translation & 34 & 17 \\
Teaching & 28 & 14 \\
\hline
\end{tabular}

As shown in Table 1, the most frequently discussed topics are linguistics, occupying around 39\% (79 in total), literature and translation about $31 \%$ ( 62 ) and $17 \%$ (34) respectively, and teaching only approximately $14 \%$ (28).

Table 2. Types of 211 undergraduate theses by 2012 English majors in NIT

\begin{tabular}{lll}
\hline Types & Total & Percentage \\
\hline Linguistics & 88 & 42 \\
Literature & 57 & 27 \\
Translation & 40 & 20 \\
Teaching & 26 & 12 \\
\hline
\end{tabular}

Similarly, Table 2 illustrates the percentage of these four topic areas - linguistics, literature, translation, and teaching - comprising nearly $42 \%, 27 \%, 20 \%$ and $12 \%$ respectively. It can be concluded from both tables that linguistics, literature and translation are the dominant topics. The reasons lie in the fact that in features modules in School of Foreign Languages in NIT, students could choose among linguistics, literature, translation, and 
international trade. Therefore, students could possibly acquire a pool of knowledge of linguistics, literature, translation, but not of teaching because of limited access to teaching practice, which would be essential for collecting and analysing data in writing thesis on teaching. Therefore writing thesis on teaching is rather difficult for students in NIT.

\subsubsection{A Lack of Focus in Thesis Topics}

Some students would choose rather broad topics, such as, The Role of Source Language in English Teaching, A Case Study of Comparing the Origins of Chinese and Western Traditional Festivals, A Study of English Teaching in High school, and A Study of Inappropriate Pragmatics in English teaching in NIT. These are examples of broad topics chosen by students and they cannot control it. No doubt, it would be difficult for students to clarify such topics within 4,000-5,000 words. In general, there is no limitation to the words used in the thesis title. However, in terms of thesis content, some titles are too broad to cover the central ideas in theses, such as a Cultural Study of Cross-Cultural Trade Negotiation. This title is too broad and do not target on any specific topics. On the other hand, some titles are too long, such as The Actress's Tragedy in A Rose for Emily from Emily's Distorted Point of View on Love. It would be better if subtitles could be added if necessary.

\subsubsection{Divergence of the Requirement of Students' Cultivation in Topic Selection}

Such topics as English Majors Applicational Talents' Training Mode under the Background of Service Learning and Roles of Chinese Immigrants Play in the Globalization go astray of the basic requirements for English major students in NIT.

\subsubsection{A Lack of Innovation in Topic Selection}

Students tend to choose similar topics and students graduating from different years would be prone to choose similar topics, such as a cliché topic - Language and Rhetoric used in Advertisements. Fewer students who graduated in the year 2011 and 2012 chose this topic, but still around ten students discussed it and some students who will graduate in 2013 would like to cover it. It seems that students have tendency to follow others' steps and would not venture in new topics from their own unique and distinct perspective. Further, in terms of literature, students are prone to discuss rather familiar works, such as Wuthering Heights, Pride and Prejudice, Gone with the Wind, and Jane Eyre. The students are particularly interested in analyzing the character, destiny, marriage views of the female characters in a literary work, or criticizing the societal or personal reasons for the tragic fate of a female character. This finding is consistent with the results from two empirical studies on graduation thesis topics by Zhang (2009).

\subsubsection{Researching Literature and Synthesising}

The researcher has been a supervisor for the past eight years, helping students with their graduating thesis. Data collection is the major obstacle in students' thesis writing. Many teachers in NIT reach consensus over this issue from their supervising experience. They further point out that students collect data from a narrow scope and they cannot distinguish major points from minor ones. Also, students cannot synthesise materials they collect. Students read very little literature, normally in low quality, which hinders students' attempts to write a persuasive and convincing thesis. Further, their thesis lacks the support of theoretical framework, because they gather literature mostly from non-academic journal articles, such as text books, ordinary journals, and even some bits of pieces of information from the internet. Thus, these theses tend to be less academic and systematic, worsening by the inappropriate citation.

\subsubsection{Research Proposal}

Data are collected from feedback from supervisors and from advisory panel from the educational bureau. The following are the problems in research proposal: divergence in goals set by cultivating requirements; broad topics; long titles that do not consistent with academic writing; a lack of rigor in the concept used in title; a lack of holistic view over the background information of topics discussed; a discussion of current research background without discussion and personal insights; a lack of research focus; the use of oral expression; irrelevancy of the literature; out-dated literature; a lack of systematism of methodology; a lack of logic in outline; a lack of consistency in outline.

\subsection{Thesis Writing in Each Part}

\subsubsection{Abstract}

There are four critical parts in thesis writing: research purpose, methodology, content and results, which are equally important in abstract in English. This thesis chooses 36 English abstracts by 2011 and 2012 graduates in NIT randomly. By examining the students' abstract in undergraduate thesis, the researcher tends to investigate 
these theses in terms of content, discourse, idiomaticity and style. Most of the abstracts written by English major students in NIT meet the requirements, but there are still some problems.

\subsubsection{Content of the Abstract}

This paper uses four elements in the abstract, that is, research purpose, methodology, content and results, as benchmark to examine students' abstract and to study individual proportion contained in it.

Table 3. The number of elements and their proportion

\begin{tabular}{lll}
\hline The Number of Elements & The Number of Theses & Proportion \\
\hline 1 & 0 & $0 \%$ \\
2 & 12 & $33 \%$ \\
3 & 12 & $33 \%$ \\
4 & 12 & $33 \%$ \\
\hline
\end{tabular}

From Table 3, it is noted that only $33 \%$ students fulfil the four elements required in the thesis, $33 \%$ students three, and $33 \%$ two.

Table 4. The frequency of the four elements

\begin{tabular}{lll}
\hline Elements & Frequency & Proportion \\
\hline Research Purpose & 33 & $92 \%$ \\
Methodology & 27 & $75 \%$ \\
Content & 36 & $100 \%$ \\
Results & 12 & $33 \%$ \\
\hline
\end{tabular}

As shown in Table 4, the most frequently discussed element is content, followed by research purpose, methodology and results. A lack of research purpose tends to make the content incomplete and lack of focus in research. Few students have clear idea of employing the appropriate method in researching, which undermines the validity of research. The most frequently omitted content is research results. For example, some students only write: "The fourth part is conclusion and prediction" without elaboration. There is another example. "This thesis tries to conduct a thematic analysis of the book, ranging from the historical background to the author's actual intention to write the book, so as to uncoil the knot of the contradiction and dig out the deep meaning that Mrs. Stowe wants to manifest, that is, what kind of ideal social system she actually wished to establish." However, what is exact ideal social system that Harriet Beecher Stowe intends to achieve? There is no answer in the abstract to that research question.

\subsubsection{Consistency of Discourse}

From the above discussion, there arises another question that the inadequacy of English abstract structure could be related to the consistency of discourse. In addition, there lies a difference in expression between English and Chinese discourse. The consistency of Chinese discourse lies in its consistence in ideas, whereas English also requires consistency in language structure, such as using conjunctions. A lack of this knowledge makes students write abstracts that are incomplete, ambiguous and lack of focus.

\subsubsection{Idiomaticity}

Language expression in abstracts reflects students' undesirable language proficiency. By discussing with students about their abstracts, the researcher finds out that students write one abstract in Chinese at first and then translate it into its English counterpart, who leads to awkward expression in English, causing misunderstandings. Further, grammatical mistakes add to ambiguity and sometimes divert the original meanings.

\subsubsection{Style}

Abstract is by nature academic writing, which should be formal and objective. Most of students can meet this requirement, but it would be better if they could write more formally. Some students still use such abbreviation 
form as "doesn't, hasn't" in "It is lack of knowledge of the other side's culture that results in the failure in communication, and they can't reach the anticipated purpose. What's more, some of the new rich regard 'fashioning to be a gentleman' as their core goal." However, no student uses such expression as "in my opinion", "I think".

\subsubsection{Keywords}

Most students select keywords from their thesis titles or abstract, but these words do not convey the contents, such as study, analysis, solution, problem, method, strategy and management. For example, in a thesis titled Strategies and Skills of English Tour Guide Presentation, the key words are: tourism; cross-culture communication; English tour guide presentation; Strategies and skills. Although such words as "tourism", "strategy and technique" reflect the content to some extent, this is definitely not the main idea in the thesis. In this case, it would be better to omit "tourism" as the key words and add such words which could reflect the main idea of the thesis.

\subsubsection{Contents}

Content is a critical part in thesis and a lens through which readers would grasp the main ideas contained in the thesis and its value and significance. Thus, contents writing should not be ignored. However, in supervising the undergraduate thesis, the researcher finds that some students have trouble in writing thesis, such as inappropriate proportion, and illogical.

\subsubsection{Research}

Undergraduate thesis should meet the three intertwined elements embedded in argumentation: argument, topic sentence and evidence. It should be noted that thesis writing should be rigorous and logical. On the contrary it would be unconvincing and unpersuasive. Students are aware of these standard criteria, but they have difficulty in achieving these. Some students do not perceive a panorama about what should be contained in thesis writing. Some students cannot express their ideas clearly, showing little unity and coherence. Some students display little consistent facility in the use of language, let alone appropriate word choice and idiomacity. Therefore, these theses stray away from the standard criteria of a good thesis.

In addition, it can be drawn from the 414 thesis samples that students do not conform to standard citation style. In China, there is no consensus over the citation style for undergraduate thesis. Different institutions and colleges make their own citation style by referencing some citation styles in China. In the discipline of English Language, citation styles are often using standard international citation styles, such as APA, MLA or Chicago Manual of Style. Before undergraduates write their theses, the foreign language department provides reference templates and tutorials for students. However, it turns out to be disappointing. Many students pay little attention to citation style and thus such problems as citation, quotation, connotation, examples, and fonts, are seen in theses, degrading the quality of thesis.

\subsubsection{Introduction}

Introduction is the first part of the content part in thesis and it aims to attract reader's attention. This part previews theme, research background, research questions and conclusions of thesis. The introduction part in students' thesis is lengthy, ambiguous in theme, background, research questions, and argumentation, which are the core elements comprising thesis writing.

\subsubsection{Literature Review}

Writing a good literature review is based on the ability in searching for the literature. Some students do not tend to use core reference paper. There are such problems shown in the thesis samples as the following but not limited to these: inadequacy of literature, literature which is not representative, reliable and scientific, inconsistency of literature, lack of perception and insight in addressing the literature and illogical and inappropriate use of language.

\subsubsection{Argumentation}

The gist in thesis is its argument, and evidence in supporting main ideas. Devoid of argumentation, thesis is not academic and scientific and a lack of evidence. Thesis results in a pool of examples, in poor quality. Appropriate, novel, persuasive, and typical evidence could support the arguments. The problems existing in thesis samples are inconsistency in argumentation and evidence, inconcise use of language and a lack of logic and consistency.

\subsubsection{Conclusion}

In general, it would be better if the conclusion could summarise the ideas correctly and show the concise use of language. There are such problems in the conclusion as exaggeration, digression, over brevity and redundancy. 


\subsubsection{Acknowledgement}

These are the problems in acknowledge. For example, "Secondly, I also appreciate researches that done by Leech, Grice, Lakoff, etc.. Without their former studies, I can't finish my study on pragmatic strategies." From this example, the awkward expression makes readers wonder who exactly students are grateful for, their masterpiece or these linguists. Then it comes the problem of style. Students do not keep consistent in formal expression. For instance, "In the process of writing this thesis, I came to realize that though I have learnt four years in the university, the accumulation in knowledge is not enough." This sentence would not be appropriate to be included in the acknowledgement.

\subsection{Oral Defence}

Besides problems in oral expression, students are unclear in expressing their argumentation in their thesis. Students do not have a solid theoretical foundation, or field research, or a comprehensiveness of theories.

\section{Discussion}

Writing graduation thesis is a systematic program which is a combination of efforts from administrators, teachers and students. Scientific administration ensures the quality of the graduation thesis; effective guidance helps to improve the quality of it; and it is students who do the writing. The researcher will discuss how to improve the English major students' ability of writing graduation thesis from the following aspects detailedly.

\subsection{Selecting the Title and Writing the Proposal}

\subsubsection{Establishing the System of Controlling and Supervising the Quality of Bachelor's Graduation Thesis}

The independent college should not copy the main university's administration system of graduation thesis. They should establish an administration system which is suitable for their own characteristics on the basis of their students' actual ability and thesis' specific requirements. They should administrate the graduation thesis like a product. People can use the graduation thesis' administration system to analyze the factors of influencing the thesis' quality to design and establish an effective system which accords with the major's features. Thus, it can make the academic administrators, teachers and students active and improve the quality of the thesis as well as the supervision of the teaching process.

\subsubsection{Selecting the Title Effectively}

The students should master the basic principles and skills of selecting the title, for instance, the good title has to be specific and novel. It is difficult and unpractical to focus on the novelty of Bachelor's graduation thesis written by independent college students. However, the thesis should include something subjective and particular, or it will be meaningless to select such a subject. Actually, novelty can be the innovation of viewpoint, perspective and means. The comparison of different viewpoints, the plunge of different perspectives, the usage of different means and the intersection of different courses can make the thesis distinct and unique. The title should be concise, clear and uncomplicated.

Moreover, in order to let the students attach importance to the selection of the title, the person in charge of the graduation thesis has to analyze and summarize the problems of the previous graduates' selection, and also analyze the new graduates' issue specifically. Thus, it can make the students understand the requirements of selecting title clearly and avoid the problems of irrelevance and covering a wide range.

\subsubsection{Making Good Use of the Library}

Guiding the students to select the title is just a minor part of writing the graduation thesis, and the major part depends on the information provided by the library. It could be said that the quality and service of the library have a great impact on students' thesis writing. The library administrators should change their previous viewpoints to improve the quality of the service and give full play to the library. They should make a contribution to improving the quality of the graduation thesis with the students from the foreign languages.

\subsubsection{Verification of the Title and Guidance of the Proposal}

\subsubsection{Verification of the Title}

The verification of the title is an extraordinary preliminary work of guiding the graduation thesis. In the process of it, the members of the title verification team should discuss the students' own perspective carefully and point out the problems and defects, and then come up with the solution as well. Thus, the irrelevance, old-fashion, ambiguity, and similarity can be avoided at the most. 


\subsubsection{Guidance of the Proposal}

Proposal defense should be arranged to point out some reasonable and practical suggestions according to the students' writing perspectives, content, relevant research developments and structure. For the students who are going to start writing the thesis, those reasonable advices can help them to have a better understanding of the whole thesis and write it more successfully. After deciding the title of both English and Chinese version, School of Foreign Languages in NIT will ask some experts to check the problems like translation.

\subsection{Writing of Every Part of the Thesis}

\subsubsection{Requirements of Writing the Abstract}

The abstract and keywords are the essence of the thesis. They are the form of expressing the main thoughts and the searching marks based on the main body of the thesis. The readers can understand the content of the whole thesis by reading the abstract so that they can master the whole thesis. In addition, the abstract can provide the information for the literature retrieval or be cited by other people directly. So the authors have to operate and refine carefully. The abstract is a complete essay that can be cited, and for the English graduation thesis, please see the following requirements: the information should be abundant, and it cannot omit the main information of the thesis; it has to reflect the novelty and uniqueness; the author should pay attention to the structural and stylistic features and not combine the the first class subject and the second class subject together to form the abstract; the author should exclude the common sense of the topic; the author cannot write the abstract like the introduction; the abstract should not only include the background and reason; the author cannot use the expression like "the author has attempted to do something", because it contains nothing meaningful; the author cannot use the First Person. For instance, "In this article I analyze/discuss/describe...."; the author should use the Third Person and The Passive Voice more.

\subsubsection{Optimizing English Curriculum and Highlighting Features of the Administration}

\subsubsection{Optimizing English Curriculum}

1) The construction of module: Teaching Syllabus for English Majors from institution of higher learning 2000 stipulates that the institution of higher learning cultivates English major students to have solid language basis and extensive knowledge and can use English masterly in the fields of foreign affairs, education, trade, culture, science and technology, teaching, administration, research as interdisciplinary talents. It demands the talents to mix the knowledge together and permeate the courses. So the university has to cooperate with School of Foreign Languages to cultivate the English interdisciplinary talents, and handle the relationship between the skill courses and knowledge courses well. The administrators can use linguistics, British and American literature, business English and translation as modules to design the cultivating plans. They should lessen the kinds of compulsory courses and add the kinds of selected courses, and focus on acquiring some other professional knowledge related with English major.

2) The construction of academic thesis writing courses: Department of teaching should strengthen construction of English academic thesis writing courses, let students know about the standard and skills and train them to write systematically. The supervisors can ask the students to submit the report according to some professional topics. It can form the training pattern of course thesis to graduation thesis by guidance, and let the students have a perceptual knowledge of academic thesis writing. School of Foreign Languages, Ningbo Institute of Technology, Zhejiang University has brought forward the graduation thesis writing to the $7^{\text {th }}$ semester since 2012, and set up the curriculum Advanced English Writing or Graduation Thesis Writing which is taught by senior Chinese teachers.

\subsubsection{Strengthening Practical Teaching}

Practical teaching should be strengthened and consciousness of thesis writing should be built. We should penetrate the basic language skills throughout the process of education, focus on the thematic learning and try to select some content-based teaching materials, from the courses of basic English skills to professional knowledge. We should guide the students to do some small research topics and ask them to collect the materials and write the report in order to prepare for graduation thesis writing.

\subsubsection{Improving the Ability}

\subsubsection{Improving Students' Ability of Writing}

It is the students who write the graduation thesis. The improvement of students' writing ability depends on their own interest in study and cultivation of thinking ability. Interest is the best teacher. For the students, they should broaden their horizon, have a profound understanding of academic research, master the trend of the field and lay 
a solid foundation for research.

\subsubsection{Improving Teachers' Own Ability of Doing Research}

The school can train teachers according to the orientation designedly, and organize the lectures of thesis writing regularly. The teachers should discuss guiding materials to form a virtuous cycle of getting improvement during the guidance and doing the guidance to students. The teachers from School of Foreign Languages could share their experience in the process of guiding thesis writing, and edit a book to guide the English major students from independent college to write the graduation thesis. It can guide the students from the perspective of graduation thesis' structure, content, language and style format.

\subsection{Defense}

During campus life, students should pay more attention to their pronunciation and accent. School of Foreign Languages has modified the pronunciation curriculum, but it is not enough. We can consider strengthening the pronunciation training in comprehensive English classes when students are freshmen and sophomores.

\section{Conclusion}

In summary, many problems exist in undergraduate students' thesis writing in both content and type. Administrators, teachers and students should made efforts collectively. For independent institutions, it is important to raise both teachers' and students' awareness in the importance in thesis writing. Teachers should shoulder the responsibility of guiding students in thesis writing and enhancing their abilities. The following effective measures will be helpful: improving the quality of teaching; perfecting the curriculum; enhancing field research; improving pedagogy; improving assessment; improving educational management; cultivating students' rigor and diligence in learning and writing; researching every requirements of undergraduate thesis writing; All these mentioned above would push English teaching practice in the undergraduate level to a new height.

\section{References}

Fang, X. B. (2012). Thesis writing by English majors. Dalian: Dalian University of Technology Press.

Higher Education Department of Education Ministry, Beijing City Board of Education. (2007). Thesis instructions for English majors from institutions of higher learning. Beijing: Economic Daily Press.

$\mathrm{Mu}, \mathrm{F}$. Y. (2001). An inquiry into and reflection on the current state of paper writing among the graduating English majors. Journal of Xuzhou Normal University (Philosophy and Social Sciences Edition), 27(4), 138-142.

Slade, C. (2000). Form and style: Research paper, reports and theses. Beijing: Foreign Language Teaching and Research Press.

The English Branch of the Teaching Advisory Board of College Foreign Language Programs. (2000). The national curriculum for college English programs. Beijing: Foreign Language Teaching and Research Press.

Yu, M. Y. (2001). Improving the administration of English majors' graduation theses. Journal of Chongqing University (Social Sciences Edition), 7(5), 40-42.

Zhang, C. F. (2009). Researching and reflections on quality of graduation theses by English majors in the last five years - A case study of a university. Journal of Chongqing Jiaotong University (Social Sciences Edition), 9(2), 141-144.

Zimmerman, R. (2000). L2 writing: Subprocesses, a model of formulating and empirical findings. Learning and Instruction, 10(1), 73-99. http://dx.doi.org/10.1016/S0959-4752(99)00019-5

\section{Copyrights}

Copyright for this article is retained by the author(s), with first publication rights granted to the journal.

This is an open-access article distributed under the terms and conditions of the Creative Commons Attribution license (http://creativecommons.org/licenses/by/3.0/). 